\title{
EL SUJETO ESCINDIDO Y LA RENUNCIA A LA NOVELA COMO TOTALIDAD (ESCRITURA FRAGMENTARIA E HIBRIDACIÓN GENÉRICA EN LA NARRATIVA DE ENRIQUE VILA-MATAS)
}

\author{
THE SPLIT SUBJECT AND THE RESIGNATION TO THE NOVEL LIKE TOTALITY \\ (FRAGMENTARY WRITING AND GENERIC HYBRIDIZATION IN THE VILA-MATAS'S \\ WORK)
}

\author{
Olalla CASTRO HERNÁNDEZ \\ Universidad de Granada \\ olalla_castroh@yahoo.es
}

Resumen: Este artículo analiza la profunda imbricación entre el desmontaje del concepto moderno de sujeto y los mecanismos textuales puestos en funcionamiento en las novelas de Enrique Vila-Matas, especialmente en su trilogía metaliteraria (bartleby y compañía, el mal de montano y doctor pasavento). Procedimientos como la escritura fragmentaria, la hibridación genérica, la intertextualidad o la autoficción, están puestos en la obra de Vila-Matas al servicio del cuestionamiento de una noción cerrada y monológica de la identidad y contribuyen así construir ese yo múltiple y en constante proceso de transformación que proponen los textos del escritor catalán.

Abstract: This article analyzes the deep connection between the disassembly of the modern concept of subject and the textual mechanisms put to work in Enrique Vila-Matas's novels, specially in his "metaliterary trilogy". Procedures as the fragmentary writing, the generic hybridization, the intertextuality or the autofiction, are put in the work of Vila-Matas to the service of the deconstruction a closed and monologic notion of the identity.

Palabras clave: Sujeto. Modernidad. Novela. Escritura fragmentaria. Enrique Vila-Matas.

Key Words: Subject. Modernity. Novel. Fragmentary writing. Enrique Vila-Matas. 


\section{LA RENUNCIA A LA NOVELA COMO TOTALIDAD}

Desde su narrativa más temprana (Impostura, Una casa para siempre), Enrique VilaMatas ha convertido el tema de la identidad en un poderoso leitmotiv de su escritura, que trabaja siempre en la dirección de disolver al yo en un marasmo de máscaras y voces ajenas, identidades provisorias que se gestan en contacto con la alteridad y siempre conteniéndola, pero que, paradójicamente, buscan desesperadamente convertirse en únicas, excepcionales, originales, a partir de la asunción de que lo propio de cada individuo y de cada escritor provendrá siempre de una particular manera de asumir a los otros dentro de sí mismo o de sus textos.

Los aspectos más evidentes de esa obsesión por la identidad del yo, concebida siempre como algo problemático y en constante proceso de transformación, han sido analizados ya por la crítica, de modo que no nos detendremos en ellos. Lo que en este artículo nos interesa especialmente es la profunda imbricación entre esa noción de identidad que domina los textos vilamatasianos y los dispositivos textuales desplegados en los textos del escritor catalán, sobre todo a partir de Bartleby y compañía. Esos dispositivos que la crítica a menudo reconoce como los más característicos de la narrativa de Enrique Vila-Matas (hibridación genérica, escritura fragmentaria, intertextualidad, autoficción...) guardan una estrecha relación con ese sujeto roto y fuera de quicio, con ese yo fragmentado y en constante proceso de descomposición-recomposición que protagoniza las novelas vilamatasianas.

La renuncia a la novela concebida como totalidad es una clara forma de resistencia y reacción de un yo que no se reconoce a sí mismo ya como sujeto (dueño y señor de su propia psique y del mundo de los objetos), como identidad clausurada y perfecta (esa mismidad concebida por la ontología sustancialista), sino que se autopercibe como ipseidad, identidad histórica y en constante proceso de cambio ${ }^{1}$, materia frágil y siempre a punto de descomponerse, que lucha, sin embargo, por mantener cierta coherencia, por no disolverse del todo en lo indistinto, tal y como reza la hermosa cita de Magris que encabeza este artículo. Creemos que todos los procedimientos narrativos de la trilogía se ponen en marcha para acometer ese desmontaje de la ilusión moderna del yo como Sujeto: desde la hibridación genérica a la estética de la fragmentación, desde la autoficción a la intertextualidad.

1 "La identidad se funda en la mismidad. Los antónimos de sí mismo son la otredad, lo distinto y diverso respecto al punto de observación. De hecho, la identidad se establece desde la otredad: las ideas del yo y del nos surgen tras las de tú y ustedes (vosotros). No obstante, el sí mismo también es otro, porque cada quién lo comprende en tanto lo imagina como su alter ego, y porque lo lleva adentro: nadie llega a conocerse del todo. Adicionalmente, a lo largo de su historia, el sí mismo va siendo otro. No somos una mismidad entendida como esencia inmutable, sino que cambiamos, vamos acumulando experiencias, nos reestructuramos. Somos, pues, históricos, tenemos una ipseidad o identidad ipse" (Palazón, coord., 2005: 21). 
Vila-Matas, como heredero de esa tradición de la Modernidad negativa (que acompaña a la Modernidad normativa desde su nacimiento) no cree ya en la falacia del mundo como totalidad, y sospecha de las formas de pensamiento que pretenden negar la complejidad irreductible de la realidad atrapándola en sus fórmulas matemáticas. Por eso abandona las formas literarias que se habían elaborado como correlato de la Razón burguesa, del pensamiento de la unidad, la totalidad y la universalidad del Cogito cartesiano. La novela realista decimonónica, artefacto que compone una imagen armónica de un mundo racionalmente estructurado, donde la historia es entendida como progresión lógica y lineal hacia adelante, donde el pensamiento causal rige el desarrollo de la trama y los personajes gozan de una psicología definida y coherente, tiene que ser desactivada una vez que la realidad ha mostrado sus fisuras:

La inoperancia del arte realista no estribaba ya en la caducidad de esa estética confiada sino en la insostenible falacia en la que se apoyaba: la de que existía una realidad objetiva que reproducía, en todo o en parte, el artista. La realidad como entidad sólida y universalmente verdadera se desplomó (Ródenas de Moya, en Heredia, 2007: 274).

La forma que había adquirido la movela (que halla su máximo grado de perfección en el realismo decimonónico) era la plasmación directa del tipo de Sujeto y de Razón construidos por el inconsciente ideológico y libidinal capitalista, como ha explicado largamente Juan Carlos Rodríguez. Antes de él, la sociología de corte marxista había señalado ese binomio novela-burguesía (Lúckacs). Algo que supo ver también el estructuralismo. En El grado cero de la escritura, Barthes apuntaba que la novela era el género por excelencia del proyecto de la Modernidad occidental y de sus sociedades burguesas:

[Existe] cierta mitología de lo universal, propia de la sociedad burguesa, cuyo producto característico es la Novela. Dar a lo imaginario la caución formal de lo real, pero dejarle a ese signo la ambigüedad de un objeto doble, a la vez verosímily falso, es una constante operación en todo el arte occidental para quien lo falso se iguala con lo verdadero, no por agnosticismo o por duplicidad poética, sino porque lo verdadero supone un germen de lo universal, o si se prefiere, una esencia capaz de fecundar, por simple reproducción, órdenes diferentes por alejamiento o ficción. Por medio de un procedimiento semejante, la burguesía triunfante del siglo pasado pudo considerar sus propios valores como valores universales e imponer a zonas absolutamente heterogéneas de su sociedad los nombres de su moral (Barthes, 2003: 39-40). 
El yo que deviene tras la crisis de la subjetividad moderna no puede reconocerse ya en la unidad formal de la novela burguesa, porque él mismo no se siente uno, sino muchos (un puñado de yoes irreconciliables que no conforman un todo armónico, sino un conjunto fragmentario y precario donde todos los elementos van cambiando constantemente de posición y de forma). Cualquier transgresión al gran estilo de la novela moderna supone un desplazamiento de la categoría de Sujeto y de Autor que domina en la Modernidad, que quiebra también la propia lógica omnicomprensiva de la racionalidad moderna y su articulación en torno a los conceptos de unidad, totalidad y orden:

La desarticulación de la totalidad quebranta el gran estilo, que es visto ante todo como la capacidad de la poesía para reducir el mundo a lo esencial y dominar la proliferación delo múltiplea una lacónicaunidad designificado. Elgranestilo constriñe y comprime las disonancias de la vida en una armonía unitaria. En este sentido el gran estilo es también violencia, en la perspectiva de Nietzsche y posteriormente de Heidegger: es la violencia metafísica de un pensamiento que impone a las cosas la camisa de fuerza de la identidad y las convierte en símbolos de un universal que viola su singularidad y su autonomía (Magris, 2012: 11-12).

En ese bello opúsculo que es Perder teorías, escrito al cobijo de Dublinesca, Ribas/VilaMatas se enumeran cinco rasgos de la novela del siglo XXI que parecen irrenunciables: la intertextualidad, las conexiones con la alta poesía, la escritura vista como un reloj que avanza, el triunfo del estilo sobre la trama y la conciencia de un paisaje moral ruinoso (Vila-Matas, 2010: 28). El desmontaje de la novela Realista, del gran estilo, se convierte en objetivo de los ejercicios de escritura que acometen los narradores vilamatasianos, en especial los que aparecen en la trilogía metaliteraria (formada por las novelas Bartleby y compañía, El mal de Montano y Doctor Pasavento), y en los tres se cumplen los requisitos que Ribas exige a la novela del siglo XXI, a los que se suman otros procedimientos, como la hibridación o mestizaje genéricos y la estética fragmentaria, que trabajan en la misma dirección de desarticulación y rearme del género novelístico desde nuevos presupuestos.

La nueva novela (esta vez ya en minúsculas) apela a una unidad que ha sido ya rota. La vida se ha mostrado atomizada, disuelta y, sobre todo, carente las más de las veces de toda lógica. Si no hay unidad en la vida ni en el sujeto (también ahora en minúsculas), las formas literarias de un yo que se siente plural y descentrado, complejo y cambiante como el resto de materia que compone la vida, no pueden tampoco proponerse como unidad clausurada, no pueden seguir configurándose desde el pensamiento de la Modernidad normativa. El fragmentarismo, la renuncia de la novela a las formas y estructuras que la representaban como totalidad, y el mestizaje genérico, se convierten en toda una 
declaración de intenciones con respecto a la propia noción de identidad en la trilogía metaliteraria:

La mezcla de géneros literarios y el desdoblamiento del yo narrativo que encontramos en El mal de Montano proceden de una de las convicciones estéticas y ontológicas más arraigadas en el autor, la que halla en el mestizaje y el fragmentarismo las únicas posibilidades que le quedan a la literatura o, lo que es lo mismo, a la identidad (...) Esto nos lleva a lo que se puede definir "otredad" del yo vilamatiano, un yo que se adhiere de manera esmerada a la máxima rimbaudiana del "yo es otro", integrándola con muchos más yoes en los que se pierde, al desdoblarse, la voz autorial. No es casual que en casi toda la producción del escritor, y sobre todo en la más reciente, encontremos la presencia de numerosos dobles, que representarían las muchas caras de un mismo ser (Cancellieri, 2007: 79-80).

Tanto en Bartleby y compañía como en El mal de Montano y Doctor Pasavento, ese alejamiento del género novelístico tal y comola Modernidad normativa lo había concebido, forma parte de la hoja de ruta que los personajes-narradores trazan para librarse de sus respectivas identidades, que sienten en todos los casos como una pesada carga, y ensayar nuevas formas de ser. La fragmentación, la hibridación, las estructuras abiertas, la renuncia a la primacía de la trama sobre el estilo, se convierten en modos de señalar que no es posible seguir dotando de una apariencia de totalidad perfecta, de unidad cerrada, de entidad acabada e irrebasable, a la novela, pues quien escribe no se autopercibe ya tampoco como unidad ni centro de todo, como Sujeto de una pieza, como mismidad, sino como yo múltiple, histórico, cambiante. Es el fracaso o la caída de la noción moderna del Sujeto y la concepción de la identidad del yo como algo fragmentado, penetrado por las fuerzas del inconsciente y por la Lengua del Amo lacaniana, lo que hace insostenible el mantenimiento de las formas y contenidos que el Realismo había otorgado a la novela como género. Y sólo si esos rasgos típicos de la escritura vilamatasiana, que se convierten en la trilogía metaliteraria en claves de sentido, son analizados por la crítica en su conexión profunda con esa crisis de la Modernidad normativa, de su Sujeto, de su Lenguaje, de su Razón, y no como meras opciones estéticas o formales, como operaciones superficiales, como problemas de dispositio, se estará penetrando en lo profundo de esa escritura, apuntando a su raíz, a su centro:

Me parecería errónea la crítica que quisiera ver en estas estructuras abiertas y en los movimientos parentéticos tan peculiares de su estilo ensayístico y narrativo un problema únicamente de dispositio, o de organización del decir. Concluir tal cosa es quedarse en la superficie o las apariencias. Por debajo de esa opción permanece 
el fondo filosófico que se hunde en la crisis contemporánea del sujeto y afronta el cuestionamiento de la metafísica de una identidad ontológica, sólida y maciza, sostenida en principios narrativos por la propia lógica de sistemas culturales narrativos (...) La elección del fragmento, la renuncia al dispositivo de identidad narrativa, como hace también Barthes cuando se trata de su biografía, quiere mostrar que el concepto de identidad está repartido, diseminado, fragmentado (Pozuelo Yvancos, 2010: 165).

Y es que, esa crisis de la Modernidad normativa que tiene lugar en los siglos XIX y $X X$, esa profunda y devastadora crítica a la que son sometidos todos los conceptos que habían surgido al abrigo de la filosofía sustancialista de la conciencia, del racionalismo cartesiano y sus posteriores reelaboraciones kantiano-hegelianas, ha de implicar, como es de suponer, que hayan de repensarse y cuestionarse las propias categorías genéricas al uso. La teoría clásica de los géneros, de herencia platónica y aristotélica, había pervivido a través de los siglos, siendo reajustada históricamente según los intereses, del inconsciente feudal cristiano, primero, y del inconsciente capitalista burgués, después. A pesar de tales reajustes y de los cambios hechos para acoger a los nuevos géneros y subgéneros históricos que iban surgiendo, la concepción tripartita de los géneros pervivía (la Modernidad reformuló la triada platónica que distinguía el género épico, lírico y trágico, y pasó a hablar de literatura épica, lírica y dramática, lo cual llega hasta la teoría contemporánea con nuevos nombres: narrativa, poesía y teatro -la triada se mantiene, aunque sea a fuerza de separar los llamados géneros de ficción de los llamados géneros de no ficción, donde entrarían el ensayo, el aforismo o los géneros periodísticos, que adquieren en la Modernidad estatuto literario, valor estético-).

Es obvio que a lo largo de la historia de la Estética han sido muchas las taxonomías genéricas y que corremos el riesgo de estar banalizando un debate complejo y de peso dentro de la propia teoría literaria (debate al que han aportado ideas, desde la Semiótica o la Estética de la Recepción hasta el Formalismo, Estructuralismo y la Deconstrucción, en el siglo XX), pero lo que nos interesa, más que tratar de condensar o reproducir las líneas maestras de ese debate, es apuntar a cómo esa crisis profunda que sufre la Modernidad ilustrada y burguesa al ser sometida a una crítica radical que se anunciaba tímidamente ya en cierto Romanticismo y que estallará definitivamente con Nietzsche, convulsionando el pensamiento de los siglos XIX y XX, afecta a las propias categorizaciones teóricas de las producciones literarias. Del mismo modo que esa imagen de la realidad como totalidad inmutable salta hecha añicos; del mismo modo que las verdades de una Razón que se pretendía universal y eterna comienzan a entenderse como históricas y lingüísticas; del mismo modo que el yo se sabe recorrido por la alteridad y por las fuerzas del inconsciente, fracturado, herido por dentro; del mismo modo que se diluyen los límites rígidos que el pensamiento estructurado por lo que Derrida llamaba la metafísica de las oposiciones del 
lenguaje racional había impuesto a toda realidad y abstracción mental (algo era algo por el mero hecho de no ser eso otro a lo que se oponía: A era A porque no era $B$, y esto era lo que lo diferenciaba de $B$, lo que determinaba su naturaleza, su particular manera de ser, su identidad) y se reivindican paradigmas de pensamiento complejo abiertos a lo paradójico, a lo incoherente, a la inestabilidad del sentido (al hecho de que algo pueda ser $A$ o parecerse a $A$ y a la vez ser $B$ o parecerse a B, hasta el punto de convertirse en una nueva realidad híbrida inclasificable ${ }^{2}$ ), también los propios géneros literarios son cuestionados como taxonomías cerradas y categorizaciones estancas.

Todorov insiste en señalar el carácter histórico-social de los géneros y los concibe como algo vivo, en constante movimiento, que sufre variaciones en función de la ideología dominante. Los géneros se transforman, nacen y mueren, no pueden entenderse como categorías estancas ni mucho menos como universales ahistóricos. También Bajtín, en Teoría y estética de la novela, concibe los géneros discursivos como articulados sociohistóricamente con corrientes ideológicas que están en la base de la heteroglosia o vida social de los discursos.

De ahí que sean, sobre todo, las narrativas inscritas en la tradición literaria de la Modernidad negativa y las vanguardias históricas, que surgen en ese contexto histórico de crisis del paradigma de pensamiento racional-ilustrado, las que vayan a esforzarse por desbaratar las rígidas prescripciones de la Estética clásica, por transgredir los límites intergenéricos, por desviarse de la ortodoxia literaria, del canon del momento, y explorar nuevas formas de narrar fuera del Realismo burgués: Sterne, Virginia Woolf, Joyce, Kafka, Proust, Thomas Mann, Musil, Walser, Melville, Unamuno, Baroja, Dos Passos, Hemingway, Faulkner, Scott Fitzgeral, Beckett, Camus, Perec, Calvino, Cortázar y Rulfo, por nombrar solo algunos, tienen en común ese afán por encontrar nuevos caminos para un género que se había anquilosado en las fórmulas del Realismo. Esa línea expedicionaria es seguida en las últimas décadas por Bolaño, Piglia, Magris, Sebald, Justo Navarro, Javier Marías, Thomas Pynchon, Coetzze o el propio Vila-Matas. Bajo distintas etiquetas, la antinovela, el Nouveau roman, el Realismo fantástico, entre otras, se tratan de catalogar desde la teoría literaria esas desviaciones deliberadas de la norma realista. Para Ródenas de Moya, son precisamente estas exploraciones de la novela en sus propios márgenes, ese afán de determinados narradores por instalarse en los límites de lo novelesco para, desde allí, intentar ampliarlo o destruirlo, lo que posibilita la propia continuidad del género: "Tanto la desestructuración de la novela como relato cuanto su mestizaje discursivo se convirtieron en las señas de identidad de su posibilidad de pervivencia" (Ródenas de Moya, en Heredia, 2007: 278).

El concepto de novela se diluye hasta el punto de convertirse en una noción vaga, que apenas se acoge, en la mayoría de sus definiciones, a cuatro requisitos: la escritura en prosa,

2 Una idea muy similar a la de entre-lugar o Tercer Espacio que vengo desarrollando en los últimos años. 
la extensión, el carácter ficcional de parte de los hechos que en ella se narran y la intención literaria o estética de su autor. Se admite así que la novela es un género poliédrico, donde concurren distintos tipos de discurso y donde de hecho pueden confluir todos los géneros (la poesía, el ensayo, la prosa periodística....). Como señala Irene Andrés-Suárez:

Creemos que no es exagerado decir que, desde el primer tercio de este siglo3, la novela es ya todos los géneros, es decir, un género sin límites [...] Sin llegar de manera indefectible a la disolución de los géneros, lo que predomina en la actualidad es la textualidad múltiple, el mestizaje y la disgregación, consistente ésta última en fundar textos a costa de formas previas cuyo resultado no es la simple adición de todas ellas sino un producto híbrido, fundamentalmente distinto (Andrés-Suárez, 1998: 10-11).

En la misma línea señalada por Andrés-Suárez, Pozuelo Yvancos concibe la poética vilamatasiana desplegada en lo que él ha llamado tetralogía del escritor (que añade a la llamada "trilogía metaliteraria" la novela París no se acaba nunca), como una summa de géneros donde confluyen todo tipo de géneros de ficción y no ficción y cuyo resultado no es simplemente la acumulación, la adición, la suma de unos géneros y otros, sino algo, como indicaba Andrés-Suárez, "fundamentalmente distinto". Pozuelo, en la línea derridiana, prefiere hablar de la escritura como género que ha rebasado por completo los límites de la novela:

[...] poética de la escritura como summa de géneros. Se dijo siempre de la novela que era tal cosa. Ahora habría que decirlo de un nuevo género, la escritura, que compone un tapiz disparado en múltiples direcciones. Si resulta difícil en su obra separar el artículo, el ensayo, la conferencia y la novela, no es porque cada uno responda a distintas formas de infidelidad a sí mismo, sino por la fidelidad que todos traman para este otro género mestizo, un hijo nacido de ellos, de su mezcla, en el que la reflexión filosófica, el trozo de periódico, el fotograma de una película, lo arrancado a un diario, lo escrito en un poema, lo autobiográfico y lo fingido como tal, lo histórico conocido por todos y lo inventado totalmente, van componiendo un mosaico que no es cada una de esas cosas, tampoco es la suma, yuxtaposición aditiva, sino la summa, que es otra cosa, un conjunto nuevo (Pozuelo Yvancos, en Heredia, 2007: 404).

3 Andrés-Suárez se refiere al siglo XX. 


\section{LAS NOVELAS DE LOS ESCRITORES QUE NO ESCRIBÍAN NOVELAS}

Efectivamente, las tres novelas que componen la trilogía metaliteraria de Enrique VilaMatas, pueden considerarse claramente esos productos híbridos y mestizos de los que habla Andrés-Suárez, esa summa de géneros a la que alude Pozuelo Yvancos. En cualquier caso, en la trilogía hay una clara intención de desmontar la novela como género desde su interior, de desactivar los mecanismos que la acercan a la estética del Realismo y activar otros muchos que actúan como pequeñas bombas, que detonadas en determinados puntos estratégicos de la narración, dan a luz un artefacto nuevo.

Las convenciones genéricas, como sabemos, actúan también como pistas para el lector, hacen que leamos de determinada manera un texto y que despleguemos un determinado horizonte de expectativas. Pues bien, la trilogía está plagada de falsas pistas que funcionan precisamente para desorientar al lector, de "acuerdos" que aparecen con el único propósito de romperse, de transgredirse después. La narrativa vilamatasiana es lo más parecido a un paisaje escarpado que recorremos sin mapa o con un mapa cuyos puntos marcados a veces sólo pretenden despistarnos, con lo que no todo lector está ni dispuesto ni preparado para explorar ese terreno arriscado.

Lo primero que los tres narradores de Bartleby y compañía, El mal de Montano y Doctor Pasavento acometen en sus respectivos textos, es una negación profunda y radical del género novelesco tal y como la Modernidad normativa lo había configurado e, insistimos, al negar la Novela que el positivismo había institucionalizado, están negando al Sujeto que el inconsciente capitalista articuló. Los tres textos se escriben en clara oposición al modelo de novela realista triunfante en el S.XIX, cuya estructura y contenido se adecuaban a la perfección tanto a la noción de racionalidad pergeñada por esa Modernidad como al tipo de Sujeto que ésta había configurado. Los tres personajes/narradores de la trilogía escriben antinovelas, niegan de distintos modos el gran estilo que había dominado en la novela realista y que, de alguna manera, sigue presente hoy en gran parte de la narrativa comercial. Esa desarticulación de la Novela tal y como la Modernidad la había categorizado (como un género estanco y separado de los demás que se adaptaba como un guante al sujeto burgués), se realiza mediante un doble movimiento que, por un lado, como hemos visto, diluye los límites trazados artificiosamente por la teoría de los géneros clásica y moderna, gracias a someter al enunciado narrativo a un proceso de hibridación/ contaminación de otros géneros (ensayo, poesía, crónica periodística, conferencia, diccionario de autores), mientras por otro lado reduce a su mínima expresión los rasgos más propiamente novelescos (como la trama, la acción o los diálogos, que desaparecen 
por completo), generando una escritura mestiza que desafía todas las concepciones y catalogaciones típicas de la teoría literaria moderna ${ }^{4}$.

No debemos perder de vista el hecho claramente significativo de que ninguno de los narradores-protagonistas de la trilogía manifieste en ningún momento su intención de escribir una novela: Marcelo escribe las notas a pie de página de un texto invisible (es decir, la suya es una escritura que busca deliberadamente mantenerse al margen de todo género, al ser un paratexto que no rodea a texto alguno, sino a un espacio vacío, que delimita una ausencia); Girondo se enreda en la redacción de un diario de viaje que acaba convirtiéndose, sin él pretenderlo, en novela, para después elaborar un diccionario de autores y una conferencia plagadas de confesiones personales y digresiones típicas del misceláneo género del diario íntimo (el protagonismo del diario como género, que se usa en el texto para subvertirse constantemente, se convierte en una clara reflexión sobre los límites del yo biográfico y el yo ficcional y, por tanto, en un cuestionamiento del concepto de identidad); Pasavento, en su huida desesperada de la que ha sido su vida de escritor de novelas hasta el momento, se entrega a una nueva escritura, secreta y privada, que busca a conciencia alejarse de lo novelesco tanto en la extensión como en el tono, para acercarse a lo fragmentario y reflexivo, a algo más próximo al ensayo o al aforismo que a los géneros propiamente narrativos (emulando los microgramas de Walser o los microensayos de uno de los personajes más interesantes de la novela, el profesor Morante). El propio Girondo, en El mal de Montano, reflexiona sobre la tendencia de cierta narrativa contemporánea a la hibridación genérica, al mestizaje discursivo y a la autoficción, y asegura que ésa es la opción estética que se le antoja en estos momentos el camino más estimulante para la continuidad del género novelesco: "Una estimulante tendencia de la novela contemporánea, una tendencia que va abriendo un territorio a caballo entre el ensayo, la ficción y lo autobiográfico: ese camino por el que circulan obras como Danubio de Claudio Magris, por ejemplo, o como El arte de la fuga de Sergio Pitol" (Vila-Matas, 2007: 189).

Ninguno de los tres narradores, pues, menciona una deliberada intención de escribir una novela, aunque los textos resultantes de los tres procesos de escritura puedan ser leídos, efectivamente, como una novela. En los tres textos se consigue, a fuerza de inscribir varios géneros y discursos en ellos, la mayoría de las veces para acabar transgrediéndolos

4 Esta mescolanza de géneros que, a la postre, lo que hace es cuestionar precisamente las propias categorías genéricas heredadas de la estética clásica y reelaboradas en la Modernidad desde la perspectiva racionalista/positivista imperante, es un rasgo que algunos críticos han considerado como propio de la escritura posmoderna. Pero no podemos olvidar que el nacimiento de la novela moderna, con Cervantes, ya desafiaba las categorías genéricas (El Quijote incluye todos los géneros existentes en su época y, además, mediante la parodia de muchos de ellos, los desmonta y subvierte). 
o parodiándolos, ese producto híbrido, mestizo, al que aludíamos. Sobre Bartleby y compañía, escribe Bolaño:

¿Estamos ante una novela, ante una colección de medallones literarios o antiliterarios, ante un libro misceláneo que escapa a las categorías preestablecidas, ante un diario de vida del autor, ante un entremezclamiento de crónicas periodísticas? La respuesta, la única respuesta que por el momento se me ocurre, es que estamos ante otra cosa, que puede ser una mezcla de todas las anteriores, y que estamos ante una novela del siglo XXI, es decir una novela híbrida (Bolaño, en Heredia, 2007: 180)5.

Aludiendo a El mal de Montano, Ferro afirma:

La novela está dividida en cinco partes: "El mal de Montano", "Diccionario del tímido amor a la vida", "Teoría de Budapest", "Diario de un hombre engañado" y "La salvación del espíritu", en cada una de ellas se aborda un género bien preciso que luego se trasgrede. El relato zigzaguea entre formas genéricas diversas: la autobiografía fallida, el ensayo crítico, el pequeño manual de teoría literaria urgente, el diccionario de autores, la colección de cuadros de costumbres, la conferencia; instalándose en una tradición borgeana, va tramando su escritura como un vasto dispositivo estratégico de leer, de pensar, de escribir sobre sí mismo como si fuera una invención literaria (Ferro, 2003: 2).

En cuanto a Doctor Pasavento, es, quizás, de las tres novelas, la que más desarrolla los elementos puramente narrativos, en todo momento llevados a lo absurdo, a lo irónico y, en ocasiones, a lo cómico. No faltan los destellos poéticos, con pasajes de un lirismo bellísimo -también demoledor y profundamente triste-, y la conexión con el ensayo y otros géneros de no ficción es clara. Andrés Pasavento reflexiona largo y tendido a lo largo de esa narración de su huida, sobre el ensayo como género surgido como producto del Sujeto moderno. De hecho, el libro comienza junto al castillo de Montaigne, donde una voz imprecisa, quizás la del fantasma de la cuna del ensayo, lo interroga sobre su afán por desaparecer. El libro se abre ya con una danza en la que entran y salen de escena un estricto tono ensayístico y un estilo narrativo con altas dosis de imaginación, cercano a la literatura del absurdo. Ambos registros discursivos se entremezclarán a lo largo de toda la novela, que finaliza con esas tentativas de suicidio que Pasavento lee a Humbol y con los papelillos de la soledad que termina escribiendo Pasavento para sí mismo

5 En el mismo sentido que Bolaño, Rafael Conte señala: "Bartleby y compañía puede ser leída como una novela -que lo es-, como un conjunto de cuentos -que también- o como una serie de anécdotas y relatos metaliterarios, que desembocan en una reflexión bastante desesperada sobre la escritura y el silencio" (Conte, en Heredia, 2007: 204). 
(que a esas alturas de la narración es ya a la vez Andrés Pasavento, el Doctor Pasavento, Ingravallo, Pinchon e incluso el doctor Yo No Soy), emulando claramente los microgramas walserianos. Esa escritura secreta y privada, fragmentaria, hecha de fogonazos reflexivos que no tratan de hilarse demasiado sino que intentan respetar el fluir mismo del pensamiento, está presente también durante toda la novela, tanto en la reflexión teórica sobre los microgramas de Walser (que sirven claramente de inspiración a Andrés), como en los microensayos que el profesor Morante escribe en el Centro de Salud Mental de Campo di Reca donde se halla recluido y que lee a Pasavento en las distintas visitas que éste le hace en calidad de doctor en psiquiatría, además de en las propias tentativas de suicidio y en los papelillos de la soledad de Pasavento. Narración y ensayo, pues, conviven en Doctor Pasavento, bajo distintas fórmulas, restableciendo una relación que muchos no sólo no consideran imposible, sino que conciben como completamente necesaria:

Narración y ensayo no sólo no se oponen, sino que se requieren, por más que sus formas canónicas hayan terminando esclerotizándose: la novela tocando todos los fondos posibles, tanto en su expresión como en sus contenidos, y el ensayo en el marco de un cientificismo que niega su propia esencia abierta, prospectiva, no exacta, en la que siempre ha de tematizarse el yo (Vázquez Medel, 2005: 90).

Doctor Pasavento se inscribe en la tradición de la novela-ensayo que, como el propio Andrés Pasavento nos indica, viene de lejos (es un artefacto narrativo claramente moderno) y tiene por modelo el Tristam Shandy de Sterne. Lo importante aquí es ver cómo Pasavento/Vila-Matas deja claro en todo momento la tradición de la que se siente continuador, una tradición profundamente moderna, presente desde el nacimiento mismo de la Modernidad (Cervantes y Montaigne), y sobre todo, cómo Vila-Matas, al señalar a la hibridación textual como un continuum en las narrativas modernas desde Cervantes hasta nosotros, está lanzando un dardo envenenado a cierta crítica posmoderna que se empeña en interpretar la mescolanza genérica como un rasgo esencial de las poéticas contemporáneas, como un invento de la Posmodernidad:

[...] podía hablar del genial creador de La vida y las opiniones del caballero Tristam Shandy. En lugar de la rue Vaneau o de improvisar una historia sin red sobre la muchacha, hablarles de Laurence Sterne, que había casi inventado con su libro la novela-ensayo, un género literario que muchos creían que era una innovación fundamental de nuestros días cuando en realidad la novela-ensayo, con su peculiar tratamiento de las relaciones entre realidad y ficción, ya existía desde que Sterne, buen lector de Cervantes y de Montaigne, la había reinventado (Vila-Matas, 2005: 43-44). 
De hecho, el pasaje en el que Pasavento reflexiona, en un ejercicio de crítica o teoría literaria, sobre la novela de Sterne, resulta de lo más evidente que, a la vez que describe la obra de Sterne, está haciendo una declaración de intenciones con respecto a su propia escritura. No hay mejor resumen de lo que es Doctor Pasavento que esas breves anotaciones que Andrés dedica a la novela de Sterne:

Me fascinaba Sterne, con esa novela que apenas parecía una novela sino un ensayo sobre la vida, un ensayo tratado con un tenue hilo de narración, lleno de monólogos donde los recuerdos reales ocupaban muchas veces el lugar de los sucesos fingidos, imaginados o inventados. $Y$ donde la risa estaba siempre a punto de estallar y de pronto se resolvía en lágrimas (Vila-Matas, 2005: 45).

Sucede lo mismo con otro pequeño fragmento en el que Andrés habla de Walser y donde vemos de nuevo la conexión de la escritura vilamatasiana con esa tradición de la Modernidad negativa que escribe con una clara conciencia de agotamiento del proyecto ilustrado, de crisis de las estructuras de pensamiento modernas que sostenían el edificio racional, de disolución y fragmentación del Sujeto, y con una clara intención de plasmar a través de las formas literarias, del estilo, de las estructuras y el lenguaje empleados en el texto, esa ruptura, esa quiebra, esa desarticulación del mundo:

Walser (...) escuchaba perfectamente el silencio, y es probable incluso que advirtiera (aunque sólo fuera de lejos) que se estaba dando una pequeña fractura o revolución en la literatura, que se estaba produciendo la desarticulación del gran estilo clásico. Yo creo que supo muy pronto que él mismo iba a descomponerse y dispersarse en múltiples fragmentos, al igual que el libro en primera persona que dijo que siempre estaba esperando escribir. Pero, en cualquier caso, ese libro en primera persona nunca fue como proyecto la clásica y soberbia y típica construcción literaria en la que se refleja la elaboración de un paisaje mental y la fuerza creativa de un yo, sino más bien un trabajo de desintegración de ese yo (Vila-Matas, 2005: 205).

Para Pozuelo Yvancos, ese tono reflexivo que adquiere la voz narrativa domina la escritura vilamatasiana; esa mezcla de lo novelesco con lo ensayístico, esencial como hemos visto en la trilogía, se convierte en una de las principales señas de identidad (junto con otros rasgos) de la escritura de Vila-Matas, desde sus novelas a sus artículos periodísticos o sus libros de no ficción: "Junto con la estructura abierta y contenido metaliterario, hay otro rasgo que será definitorio: la voz conseguida no es novelesca pero no deja de ser narrativa, si bien proyecta sobre su materia una mirada típicamente reflexiva que provendría del ensayo" (Pozuelo Yvancos, 2010: 151). 
En la trilogía metaliteraria vilamatasiana, la novela no sólo se cuestiona como género que se ha esclerotizado (como señalaba Vázquez Medel), en sus versiones históricas modernas de mayor éxito (realista y costumbrista), y se reformula a fuerza de mezclarse con otros géneros o de diluir las fronteras entre ficción y realidad (confundiendo lo autobiográfico con lo apócrifo y entreverando elementos narrativos y ensayísticos, es decir, elementos propios de un género de ficción con elementos propios de otro de no ficción); también se acometen en los tres textos otros atentados contra la Novela que tiene al Realismo como modelo: las estructuras abiertas (a las que apuntaba el profesor Pozuelo), la escritura que se ramifica a fuerza de digresiones, que en lugar de avanzar en línea recta se expande de forma arborescente e irregular (pareciendo que a veces fuera hacia atrás y otras hacia adelante, incluso que a veces se parase en seco y se negase a seguir caminando), la reducción de la trama a la mínima expresión (lo que Vila-Matas llama el triunfo del estilo sobre la trama) ${ }^{6}$, el gusto por cierta estética de la fragmentación..., son otras formas de negar la novela como totalidad.

Pozuelo Yvancos ofrece una interesante clave de lectura para Bartleby y compañía y El mal de Montano, perfectamente aplicable también a Doctor Pasavento, que apunta a la narración como un dispositivo de fuga permanente (como esa Fuga sin fin de Joseph Roth que Pasavento menciona de forma recurrente). Lo escrito está funcionando constantemente como una culebrilla, como ese animal resbaladizo que no deja de moverse, escapándose siempre de las manos que pretenden asirlo (como escapa para Vila-Matas la literatura a toda determinación esencial, como escapa la vida que constantemente fluye a todo sentido rígido y estable que intentemos buscarle). Ya vimos cómo la ironía era uno de los mecanismos más empleados por Vila-Matas en la trilogía para desestabilizar un sentido (esa ironía que sobrevenía siempre tras una frase con visos de sentencia, tras un argumento que comenzaba a tomar forma de Verdad o de absoluto) que oscila permanentemente, sin recalar casi nunca en un lugar demasiado exacto (en El mal de Montano, la escritura se desmiente a sí misma constantemente, vuelve atrás cada tanto para aclararnos que nos había mentido, que lo que había hecho pasar por cierto ante el lector, realmente no lo era). También la propia arquitectura de la trilogía funciona como esa culebrilla resbaladiza. Pozuelo Yvancos afirma que Vila-Matas:"Rompe la barrera de los géneros sometiendo a la novela a un dispositivo de fuga permanente

6 Interesante el comentario de Dora Simion sobre la prevalencia de la dispositio en los textos narrativos vilamatasianos, siempre que pongamos en relación esta reflexión con aquélla que veíamos con anterioridad de Pozuelo Yvancos, en la que se invitaba a los críticos a indagar en el fondo filosófico sobre el que se levantaban esa arquitectura novelesca de Vila-Matas, esas operaciones de dispositio: "Una de las dimensiones fundamentales de la creación vilamatasiana es la preocupación permanente por la estructura, la arquitectura misma, es decir, por la operación de dispositio, ya que el acento se desplaza del qué argumental al cómo estructural, de la fábula al discurso. La composición suplanta la reproducción de lo real y la novela es una novela artefacto" (Dora Simion, en Ríos Baeza, 2012: 43) 
de cualquier centro, disuelta en el comentario personal entreverado de citas de lecturas" (Pozuelo Yvancos, en Heredia, 2007: 270).

Al comienzo de Doctor Pasavento, Andrés, en su reflexión sobre la narrativa de Sterne, sienta las bases del que será el procedimiento por excelencia de su propia escritura, la digresión, que concibe como huida de ese centro, como fuga permanente del sentido estable, de las conclusiones definitivas; del cierre, pues, de la narración: "Tal vez el gran invento de Sterne fue la novela construida, casi en su totalidad, con digresiones, ejemplo que seguiría después Diderot. La divagación o digresión, quiérase o no, es una estrategia perfecta para aplazar la conclusión, una multiplicación del tiempo en el interior de la obra, una fuga perpetua" (Vila-Matas, 2005: 44).

Esa novela híbrida que desafía las configuraciones teóricas y las categorías genéricas, mostrando que la literatura es, como la vida, un tejido continuo donde los límites, las fronteras, están más desdibujadas de lo que la lógica racional se ha permitido aceptar, en su afán por dejar de pensarse como totalidad, se niega también a presentarse estructuralmente como unidad ordenada, clausurada, perfecta e independiente completamente del resto de obras, no sólo de su autor, sino de la tradición literaria toda. Vila-Matas se niega a presentar cada novela de la trilogía bajo ese aspecto de unidad perfecta y clausurada, porque sabe que la escritura de un autor conforma un tejido, una red, donde unos libros apelan a otros y los finales, los cierres de cada obra, nunca lo son del todo. La digresión actúa siempre abriendo la estructura de una obra, aplazando el final, la conclusión, por eso es el procedimiento predilecto de Vila-Matas en la trilogía metaliteraria (en el caso de Bartleby y compañía, los comentarios a citas y lecturas que siempre remiten a otras citas y lecturas que inspiran nuevos comentarios, convierten la estructura del libro en infinita).

Al igual que se niegan los géneros como compartimentos estancos y separados los unos de los otros, se niega cada obra como unidad completamente autónoma que sólo remite a ella misma, que se abre y se cierra en sí misma, para abrazar esa noción blanchotniana de la obra como algo que nunca termina de escribirse y que hace que el proceso de escritura sea siempre uno (incluso el silencio de un autor forma parte de su obra), el mismo, siempre inacabado. Tampoco las obras son completamente autónomas dentro del sistema literario en que se inscriben: forman parte de un continuum donde todas las obras de todos los autores forman un tejido semiótico, se trenzan.

La propia estructura de las tres obras que componen la trilogía, cada una respondiendo a un complejo plan propio, desobedece la lógica racional del principio, nudo y desenlace y se resiste a cerrarse del todo sobre sí misma. Los finales de las tres novelas no son movimientos de oclusión, sino de apertura. Innegable resulta esto en el caso de Bartleby y compañía, de la que el propio Vila-Matas ha dicho que posee una estructura infinita y que, en cierto modo, consigue volverse infinita al dejar en manos 
del lector la recopilación de nuevos bartlebys. El mal de Montano, con ese final rotundo que se convierte en una consigna para la resistencia de la literatura ("Con Praga nunca podrán"), señala hacia la continuidad de la escritura como posibilidad, con lo que se abre como futura materia narrativa aún por explorar. El final de Doctor Pasavento, con ese "pero se queda, pero se va", convierte en incierto el momento de la desaparición, de la despedida, dejando suspendida en el aire la narración. En los tres casos, como observa Dora Simion, las estructuras de las novelas son abiertas y el sentido, por tanto, nunca queda clausurado:

Las estructuras son abiertas, aunque parezcan cerradas. Se emplea una técnica permanente de fuga y desvío, una estrategia que consta de envolver la trama y trascenderla cada vez que aparece una ocasión. Es lo que llamamos la estrategia del pretexto narrativo, y que instituye un género de narratividad laxa, elástica y flexible, que ni semántica ni estructuralmente, impone condiciones férreas, rígidas e inexpugnables. Esta estructura permite las incidencias, coincidencias y casualidades, y vive plenamente del malentendido, de la mudanza, de la confusión creada por la improvisación (Dora Simion, en Ríos Baeza, 2012: 56).

Pozuelo Yvancos, en el artículo Vila-Matas en su red literaria, entiende la obra de Vila-Matas como un comentario al arte de la novela. Para él, el propósito de la narrativa vilamatasiana es desmontar la noción de necesidad que sustenta la trama y sustituirla por lo caprichoso, lo azaroso, lo contingente. En la trilogía, prima la anécdota sobre el argumento o la trama novelesca al uso. Así, se deconstruyen los mecanismos de la ficción realista moderna desde el interior de dispositivos textuales que pueden ser leídos como novelas, pero que transgreden constantemente el género.

\section{LA UNIDAD QUEBRADA DEL MUNDO Y LA ESCRITURA FRAGMENTARIA}

Otro elemento esencial de negación de la novela como totalidad en la trilogía, es el uso del fragmento, el gusto por cierta estética de la fragmentación. La crisis del Sujeto moderno aparece en la trilogía, como estamos viendo, de muy distintos modos. La ruptura con una identidad fija y estable se consigue también a través de los elementos formales, estructurales, compositivos. Hemos visto cómo las tres novelas poseen estructuras abiertas, finales que funcionan como cuadros con múltiples puntos de fuga que se disparan hacia todas las direcciones posibles, y cómo la disolución de las fronteras intergenéricas contribuye a plasmar en la escritura esa concepción del mundo, de la vida, como un tejido interrelacionado sin límites fijos o estables (un tejido similar al 
que relaciona al yo con los otros). De la misma forma, el uso del fragmento desbarata la unidad estructural de la novela.

Ese gran estilo que se plasmaba en la concepción de la novela como unidad y totalidad, el gran estilo de la Novela Realista moderna, es sustituido en la trilogía por una escritura fragmentaria que representa a nivel formal un discurso que renuncia a pensarse a sí mismo como un todo, que abraza lo inconcluso y rechaza lo unitario: un discurso que corresponde ya a un sujeto que se sabe escindido y fragmentado, roto en su interior e incapaz de ordenarse o recomponerse a través de un relato unificado y coherente, lineal, autoconclusivo, cerrado 7 .

La estructura fragmentaria se opone al todo sistémico de la Novela Realista: es una unidad frágil e inestable, que puede leerse de forma independiente, pero que sigue conectada, aunque no ya por necesidad o causalidad lógica, con el resto de fragmentos que constituyen el conjunto narrativo, cuyo orden es en cierto modo intercambiable (ya que el conjunto es siempre un conjunto abierto que podría haberse conformado a partir de diferentes combinaciones). El fragmento es un elemento ambivalente, parte y todo a la vez, que permite burlar esa lógica dicotómica que impone el Cogito del racionalismo. En el fragmento, además, significa tanto lo que se dice como lo que se omite, el lenguaje y su vacío, sus huecos. Escritura que se desvela como potencialidad de sentido, virtualidad semiótica, en tanto inconclusa, incompleta, y que requiere del lector un esfuerzo para completar los silencios, para llenar los huecos, para hilvanar el tejido deshilachado en que convierte al texto:

Por un lado, en su desafío jerárquico a la totalidad, el fragmento se afirma a la vez como todo y parte: su independencia formal y semántica no niega su implicación con un entramado textual mayor (la obra fragmentaria) en el que está contenido. Por otra parte, en la parcialidad que su propia forma reivindica, el fragmento es palabra al tiempo que silencio, información textual y omisión informativa. El contenido del fragmento se desborda, no cabe en los límites de su forma ni se corresponde con el mensaje desuspalabras - "contienemás delo queescapaz", dice Lévinas. Elfragmento no es literal: en su frágil textualidad se desencadena una virtualidad semántica que atraviesa su textura y lo lleva más allá de sus contornos. La dimensión virtual del

7 Como explica Fernández Folgueiras en su artículo: "La cuestión de la ballena: el despliegue hermenéutico de la escritura fragmentaria", en realidad, la apariencia de unidad de la novela del gran estilo es falaz. Todo texto es fragmentario: "Es difícil confiar en que un texto literario se explique a sí mismo: incluso las narraciones realistas contienen brechas, cortes o presuposiciones, huecos o indeterminaciones intrínsecas que las convierten en estructuras inestables y que descubren la segunda dimensión fragmentaria en que se define lo literario. Una fragmentación interna que las propuestas de corte más experimental, formalmente fracturadas o inconexas, sólo se preocupan por evidenciar" (Fernández Folgueiras, 2011: 172). 
fragmento - lo que no dice, su silencio — es lo que pone en marcha el movimiento hermenéutico del lector, y garantiza el vínculo entre la forma fragmentaria como realidad material o lingüistica, la totalidad literaria de la que forma parte, y un sentido que trasciende fragmento y totalidad (Fernández Folgueiras, 2011: 172).

La escritura fragmentaria en la trilogía vilamatasiana está ligada entre sí al conjunto narrativo del que forma parte por un delgado hilo, que parece siempre débil y a punto de romperse, urdido por lo anecdótico y accidental (especialmente en el caso de Bartleby y compañía). Generar un discurso dispar, que parece hecho de retazos de discursos disímiles con apariencia de haber sido cosidos al azar unos junto a otros (y en este caso la apariencia es una palabra clave, pues apenas nos detenemos y profundizamos un poco, nos damos cuenta de que nada se ha dejado al azar en la arquitectura de las tres novelas, de que las operaciones de dispositio responden a un concienzudo plan), es la única manera que encuentra el escritor de narrar de forma honesta el mundo, ese tejido de la vida igualmente dispar y discontinuo, que no cesa de cambiar y transmutarse. El propio Pasavento explica cómo para que la escritura contemporánea ofrezca una imagen verosímil del mundo, el autor ha de mostrar esa fracturación del yo, esa desintegración de la vida de la que la Modernidad negativa había dado cuenta: "El monsieur y yo creemos que el mundo se halla desintegrado, y sólo si uno se atreve a mostrarlo en su disolución es posible ofrecer de él alguna imagen verosímil" (Vila-Matas, 2005: 222).

El fragmento se constituye en la forma idónea para mostrar esa vida atomizada, esa unidad imposible, rota desde siempre, y la fragmentación misma de un yo que ha dejado de sentirse Uno para sentirse múltiple, atravesado por la alteridad. Las leyes de la lógica racional que regían la estructura, la forma y el contenido de la narrativa moderna, son abolidas por completo en la escritura fragmentaria. Lo azaroso, lo contingente, lo absurdo, lo caótico de una realidad que no puede ser contenida ni apresada por esa Razón que pretendía tener la fórmula para cuantificarlo y ordenarlo todo, se introducen en la novela, cambiándola por completo. El fragmento cuestiona la racionalidad de la Modernidad normativa y sus certezas universales y eternas, trabaja royendo desde el interior del lenguaje las estructuras del pensamiento sustancialista y esencialista como una termita de tal modo que, aunque en apariencia ese lenguaje siga intacto, en lo profundo ha sido carcomido, de tal modo que la estructura ha sido vaciada por dentro:

Con la escritura fragmentaria nos enfrentamos a la imposibilidad de la totalidad, a la destitución del ideal de completitud, al reconocimiento de la ausencia de un todo. Ella supone hacerse cargo de lo que tiene de imposible el libro como unidad. Del fragmento emana la vocación por lo no concluido, el rechazo o resistencia a la forma del gran relato, de la historia. El habla del fragmento está, además, necesariamente 
vinculada al pensamiento de la no certeza, que desdeña las seguridades ontológicas, que perdió toda confianza en los principios de la razón, que no se ajusta a ningún sistema (Salas, 2009: 174).

Por eso el fragmento (presente en gran parte de esa narrativa que da cuenta de la la crisis de la Modernidad normativa, de sus certezas ontológicas, de su Razón y su Sujeto) no puede considerarse un producto elaborado por esa factoría de la Posmodernidad que pretende a estas alturas haber inventado la pólvora. Y, aunque es cierto que el fragmento se ha convertido en la forma predilecta de la escritura contemporánea (hay un claro auge de las formas fragmentarias en las últimas décadas: microrrelatos, aforismos, las distintas reelaboraciones del haiku en la poesía occidental, experimentos formales híbridos en la línea del proyecto Nocilla Dream...), incluso, a veces, en una moda vacía que parece buscar tan sólo cierto efecto de velocidad, de celeridad, de vértigo (imitando el ritmo impuesto por los discursos audiovisuales, el lenguaje del vídeo-clip, del cine o la publicidad) y que se consigue forzando en demasía la estructura narrativa, plagándola de saltos temporales y elipsis, también lo es que, contra la aparente unidad indisoluble, linealidad y cerrazón de la Novela moderna, del gran estilo del realismo, ya se levantaron muchas voces en plena Modernidad: así, no sólo los aforismos y los fragmentos de tono reflexivo o ensayístico de Pascal, Montaigne, el propio Nietzsche o Benjamin, sino gran parte de la narrativa de finales del siglo XIX y de casi todo el siglo XX y, sin duda, todos los referentes literarios del propio Vila-Matas, recurrieron a un estilo que ponía en jaque la estructura cerrada y lineal de la novela moderna y que apostaba por lo fragmentario, lo abierto, lo híbrido:

Las consideraciones de Adorno sobre lo fragmentario del ensayo pueden ser trasladadas a ciertos modos literarios ficcionales, que, sobre todo en el ámbito de la narrativa, dan visibilidad a sus brechas y explicitan la fragmentación interna tanto en la discontinuidad de su forma como en la desconexión causal entre sus episodios. Escritura discontinua que, aunque la inexactitud crítica sitúa en el espacio de la "postmodernidad", tiene su origen en eso que Blanchot denominó el "desobramiento romántico" del círculo teórico de Jena. En este contexto el fragmento adquiere estatus de género y conquista una ambigua suficiencia que lo convierte en una forma autónoma, ya no nostálgica de una totalidad que articularía su sentido. Este vuelco romántico me permite considerar el fragmento como la estructura fundamental de los textos quebrados que proliferan a partir del siglo XX (Fernández Folgueiras, 2011: 172-173). 
Es quizás en Bartleby y compañía, la novela más fragmentaria e intertextual de la trilogía, donde Vila-Matas da cuenta de esa crisis de la subjetividad cerrada y unívoca que había configurado la Modernidad a través, sobre todo, del estilo y las técnicas narrativas, de los elementos formales o arquitectónicos, mucho más que tematizando la cuestión de la identidad del yo (en El mal de Montano y Doctor Pasavento, sin embargo, sí existe una reflexión explícita sobre la identidad), aunque en el fondo se trata de un libro que reflexiona sobre el silencio, sobre la imposibilidad de la literatura (un libro cuyo mensaje último viene a señalarnos una curiosa paradoja: si queda un camino posible para la escritura, ése sólo puede ser el que convierta en materia literaria la imposibilidad misma de la escritura, las taras del lenguaje, la caída de la vieja ilusión de que la palabra podía contener la vida, representarla en su totalidad).

A nuestro modo de entender, en la primera parte de la trilogía, la escritura fragmentaria batalla sin tregua contra el gran estilo de la Novela moderna, contra esa plasmación formal de los conceptos de totalidad y unidad con los que se configuran, tanto el Sujeto moderno como su Razón. La voz narrativa de Marcelo engarza cual orfebre las 86 piezas que componen esa pequeña joya literaria que es Bartleby y compañía. Es el contingente discurrir de la mente de Marcelo, al que el recuerdo de una lectura o de una anécdota le lleva a otra y ésta a la siguiente, por vericuetos en ocasiones completamente subjetivos y caprichosos, el que dota de coherencia el relato y ofrece esa continuidad a la narración:

En Bartleby y compañía muchos entre los 86 relatos sobre autores que enmudecen corresponden a las características de un microrrelato si recurrimos a las definiciones habituales. Por otro lado, estos relatos cortos son todos "fragmentarios" en el sentido que David Lagmanovich presta a la palabra. Pero cada uno de ellos contribuye al conjunto narrativo fragmentado que como tal ilustra lo problemático que es todo tipo de escritura novelesca en nuestros días. Múltiples reflejos de recuerdos literarios cuyo conocimiento se supone en el lector, y numerosas interrelaciones entre los casos alegados determinan el lugar de cada uno de ellos en este conjunto mientras que un narrador ficticio que comparte aparentemente un caudal impresionante de lecturas con el autor Vila-Matas y es el mismo el protagonista de uno de los casos referidos, sirve de voz narradora que garantiza una unidad de tono en el que la sátira grotesca es matizada por una punta de humor resignado (Wentzlaff-Eggebert, 2007: 120).

Sin embargo, aunque de manera menos evidente, también la escritura fragmentaria está presente en El mal de Montano, tal y como Ferro señala certeramente: "El mal de Montano es un libro fragmentario, hecho de restos de lecturas, de desvíos de géneros, de deslizamientos y pasajes entre el mundo y el texto. La novela se presenta separada en secciones, siempre incompletas y en constante proceso de mutación genérica"'(Ferro, 2003: 2). 
En Doctor Pasavento, la escritura privada a la que aspira Andrés, tan próxima a los microgramas walserianos, también pone en jaque la estructura lineal, progresiva, lógica, secuencial, causal, de la Novela Realista moderna, que obedecía ciegamente a las consignas de esa Razón omnímoda y universal, de ese Cogito cartesiano que con Kant y Hegel alcanzará su punto más alto (a la vez que, como vimos, tocará techo y comenzará su irremediable caída). Pasavento huye de su identidad de escritor de novelas de éxito $y$, para ello, lo primero que hace es buscar nuevas formas de escritura fragmentarias, breves, donde el tono ensayístico domine sobre el narrativo:

Pero para el escritor que huye de la identidad de ser escritor no le está vedado o prohibido una escritura en el silencio, sin público ni lectores. Incluso si Matas comprende que el gran novelón ha sido desactivado, la ilusión literaria ultrajada, aún queda un último reducto por conquistar: la literatura minimalista: los aforismos, los pequeños cuentos o poemas, escritura enigmática, microgramas, como Walser, pequeñas notas sobre el mundo que caben en un papel de fumar, haikus a contrapelo (Navarro Casabona, 2008: 141).

Tanto los microgramas walserianos como los microensayos que escribe Morante y lee a Pasavento durante sus visitas al sanatorio mental en el que el profesor se encuentra recluido, así como las tentativas de suicidio y los papelillos de la soledad que terminará escribiendo el propio Andrés, son textos fragmentarios, sin principio ni fin claros; textos erráticos, que no se dirigen a ningún sitio, en los que el sentido oscila y el pensamiento se desparrama sin contenerse, ajenos a la teleología de la Novela moderna: "Le gustaba, me dijo, ese tipo de microtextos que él ponía en marcha como si se tratara de un paseo errático en el que, en cualquier momento, si le apetecía, podía irse por las ramas, pues a fin de cuentas no sabía en ningún momento adónde se dirigía, suponiendo que fuera a alguna parte" (Vila-Matas, 2005: 102-103).

Morante escribe microensayos precisamente porque pretende echar abajo la vieja ilusión moderna del orden y el sentido. Si nuestras vivencias no pueden entenderse como episodios cerrados, lógicos, secuenciales, ¿por qué la narración de las mismas habría de presentarse bajo la imagen del argumento?:"No estaba claro que cualquier fragmento de nuestra vida fuera precisamente una historia cerrada, con un argumento, con principio y con final" (Vila-Matas, 2005: 103). El fragmento, a la manera blanchotniana, funciona a la postre como un rastro que se borra a sí mismo, una obra que busca desobrarse, la única forma posible para señalar hacia la imposibilidad misma de la escritura:

El fragmento no como clausura sino la infinita continuidad de lo fragmentario; la escritura no como obediencia a la ley sino como radical escepticismo y exposición al 
afuera; la obra no como un reflejo de sí mismo, sino como el interminable desobrar de aquello que, disperso, siempre difiere de sí mismo. Lo fragmentario, en otras palabras, no es un género literario, crítico o filosófico identificable, sino una demanda espectral inexistente como tal, pero que más allá de la estética o la ontología, se inscribe continuamente, tiempo al filo del tiempo, como un límite en el límite, para nunca ser asido como tal, siempre borrándose como un rastro imposible: un rastro de lo imposible (Hill, 2012: 257).

Pero, sobre todo, el fragmento es lo único que le queda a un sujeto que ha visto el mundo descomponerse en pedazos, que ha renunciado a concebir la vida como una totalidad clausurada y perfecta, que incluso se siente quebrado, escindido en su propio interior. ¿Cómo podría ese sujeto herido y desasido de sí, ese sujeto roto seguir sosteniendo una escritura concebida como unidad cerrada, como totalidad, como narración lineal y ordenada? A un yo descompuesto en su interior le corresponde una escritura abierta, que rebase los límites génericos, que se componga de fragmentos y que no concluya nunca, como nunca termina de cerrarse la propia construcción de su identidad múltiple y camaleónica.

\section{CONCLUSIONES}

La narrativa de Enrique Vila-Matas fluctúa entre la imagen rígida y estática que del sujeto construyó la Modernidad y ese sujeto fragmentado, múltiple, escindido, de las teorías posmodernas. El yo que protagoniza las novelas vilamatasianas se siente recorrido de punta a cabo por la alteridad, por la palabra ajena, por la mirada del Otro, y busca a toda costa desprenderse de su propia identidad, ser otros, para hallar paradójicamente una manera única y excepcional de ser él mismo. Y en esa búsqueda, ese yo que es casi siempre (lo es sin duda en la trilogía metaliteraria, pero también en las novelas posteriores, desde Dublinesca a Kassel no invita a la lógica, protagonizadas todas por escritores) un sujeto que se construye y deconstruye en la escritura, que se deshacey rehace a fuerza de narrarse a símismo, elige un tipo de narración muy concreta, despliega unas estrategias textuales particulares, estando los problemas de dispositio en los textos de Enrique Vila-Matas claramente ligados a la tematización del yo que domina su escritura. Tanto la elección de una escritura que diluye los límites entre los géneros literarios como la apuesta por la digresión y el fragmento, están claramente ligadas a ese modo de entender la construcción de la identidad como un proceso que no concluye nunca, que se transforma permanentemente, yal yo como un ser fragmentado, descentrado, que, como decía Hegel, "contiene en sí una multitud". Las formas literarias ideadas por la Modernidad canónica y por su Sujeto-Cogito, la Novela entendida como totalidad orgánica, no sirven ya a ese yo que se siente huérfano de la verdad y el sentido, que percibe el mundo como un caos informe, que se siente herido y descompuesto en su interior. 


\section{REFERENCIAS BIBLIOGRÁFICAS}

ANDRÉS-SUÁREZ, I. y CASAS, A. (eds.) (2007). Enrique Vila-Matas. Grand Séminaire de Neuchâtel. Coloquio Internacional Enrique Vila-Matas. Madrid: Arco / Libros.

BARTHES, R. (2003). El grado cero de la escritura. Barcelona: Siglo XXI.

CANCELLIERI, N. (2007). "La literatura o la vida. El mal de Montano de Enrique Vila-Matas como declaración de poética". En En teoría hablamos de literatura, Actas del III Congreso Internacional de Aleph, C. Morón y J.M. Ruiz (coords.), 76-82. Granada: Dauro.

FERNÁNDEZ FOLGUEIRAS, E. (2011). "La cuestión de la ballena: el (des)pliegue hermenéutico de la escritura fragmentaria". Revista Tales 4, 169-181.

FERRO, R. (2003): "El mal de Montano de Enrique Vila-Matas: ¿Homenaje a Emilio Renzi?".

Revista Hispanista 18 (julio-septiembre). Disponible en: http://www.hispanista.com.br/ revista/artigo157.htm [01-01-2015].

HEREDIA, M. (ed.) (2007). Vila-Matas portátil, un escritor ante la crítica. Barcelona: Candaya. HILL, L. (2012). "Del fragmento a lo fragmentario: Blanchot, Schlegel, Nietzsche". Instantes y Azares: Escrituras Nietzscheanas 11, 251-265.

MAGRIS, C. (2012). El anillo de Clarisse. Tradición y nihilismo en la literatura moderna. Pamplona: EUNSA.

NAVARRO CASABONA, A. (2008). "El silencio y las líneas de fuga en la escritura de Enrique VilaMatas. En Pensamiento literario español del siglo XX, 2, Anexos Tropelías, E. Sullà, T. Blesa y A. Saldaña (eds.), 135-146. Zaragoza: Universidad de Zaragoza.

PALAZÓN, M. R. (coord.) (2005). Paul Ricoeur, palabra de liberación. México: UNAM.

POZUELO YVANCOS, J. M. (2010). Figuraciones del yo en la narrativa: Javier Marías y E. Vila-

Matas. Valladolid: Secretariado de Publicaciones de la Universidad de Valladolid.

RÍOS BAEZA, F. (ed.) (2012). Enrique Vila-Matas, los espejos de la ficción. México: Ediciones

Eón.

SALAS GUERRA, M. C. (2009). La escritura del desasosiego: una poética del pensar en

Fernando Pessoa. Medellín: Editorial Universidad de Antioquía.

VILA-MATAS, E. (2005): Doctor Pasavento. Barcelona: Anagrama. (2007). El mal de Montano. Barcelona: Compactos Anagrama. (2010). Perder teorías. Madrid: Seix Barral.

WENTZLAFF-EGGEBERT, CH. (2007). "El microrrelato como fragmento de un amplio conjunto narrativo en Bartleby y compañía de Enrique Vila-Matas". Olivar 9, 105-123.

Recibido el 8 de enero de 2015.

Aceptado el 30 de septiembre de 2015. 